\title{
Levels and Sources of Language Anxiety and Fear of Negative Evaluation among Iranian EFL Learners
}

\author{
Mohammad Bagher Shabani \\ IKI university of Qazvin, Qazvin, Iran \\ Email: Shabani_M_B@yahoo.com
}

\begin{abstract}
Anxiety, as an important affective variable, has been found to be a significant factor adversely affecting language learning (Aydin 2008). Many studies have explored sources and causes of anxiety among learners (Young, 1991; Tanveer, 2007; Aydin 2008; Williams\& Andrade, 2008). However, to date little, if any, studies have examined levels and sources of anxiety and its relationship with fear of negative evaluation. To this end, the present study has been conducted in Iranian context. Data were gathered through administering two scales. Foreign language anxiety classroom scale (FLACS) and fear of negative evaluation (FNE) scale were administered to a sample of 61 EFL learners. To analyze data, descriptive statistics and inferential statistics, i.e. independent sample t-test, were run. Descriptive analysis indicated that participants suffer from language anxiety and fear of negative evaluation. The result of independent sample t-test showed there was no significant difference between males and females in the levels of anxiety. The computation of means and standard deviations of statements in questionnaires revealed that the prime sources of language anxiety and fear of negative evaluation are fear of failing class and fear of leaving unfavorable impression on others, respectively. Furthermore, Pearson correlation analysis indicated there is a significant correlation between foreign language anxiety and fear of negative evaluation. The present study will examine the causes of anxiety of students through the various types of anxiety that the students encounter in relation to learning English in a foreign land. Specifically, the research will look into foreign language classroom anxiety and fear of negative evaluation, as well as to determine the relationship between the two.
\end{abstract}

Index Terms - foreign language anxiety, fear of negative evaluation, sources and causes

\section{INTRODUCTION}

The definition of anxiety is difficult as it can range from an amalgam of overt behavioral characteristics that can be studied scientifically to introspecting feelings that are inaccessible (Lader, 1975). Therefore, anxiety can be described in a large scope. Anxiety as an affective state is defined as an uncomfortable emotional state in which one perceive danger, feels powerless, and experiences tensions in the face an expected danger (Blau, 1955). "Psychologists describe anxiety as a state of apprehension a vague fear that is only indirectly associated with an object' (Tanveer, 2007). And Young (1991) defined it in this way: it is a complex and multidimensional phenomenon and can be defined as a subjective feeling of tension, apprehension, nervousness, and worry associated with an arousal of the automatic nervous system.

Anxiety can be classified into three types. Trait anxiety is viewed as an aspect of personality. State anxiety is an apprehension experienced at a particular moment in times as a response to a definite situation (Spielberger, 1983). Finally, the last of the three types, situation- specific anxiety is related to apprehension unique to specific situations and events (Ellis, 1994). Gardner and MacIntyre (1993) describe the concept as the apprehension experienced when a specific situation requires the use of a second language in which the individual is not fully proficient. Anxiety has been found to interfere with many types of learning but when it is associated with learning a second or foreign language it is termed as second or foreign language anxiety. With the shift of research focus from teachers to learners in second language acquisition and learning, affective factors such as attitude, motivation and anxiety were thought to account for successful language learning outcomes. Anxiety, considered as one of the most important factors, has been studied since the 1970s. Macintyre and Gardener (1994) in a study they conducted involving 97 students learning French, found that those students with language anxiety find it more difficult to express their own views and tend to underestimate their own abilities. Philliphine ESL Journal, Vol. 7, July 2011. 2011 Time Taylor International ISSN 1718-229896. They also discovered that in the process of three stages of language acquisition, that is, input, processing and output, anxiety and learning achievement are negatively correlated (Macintyre \& Gardener, 1994 as cited in Pappamihiel, 2002). Pappamihiel (2002) conducted a study on language anxiety among 178 middle-school Mexican immigrant students attending school in the US. Participants were subjected to the English Language Anxiety Scale to identify how levels of anxiety correlated with specific factors such as years of stay in the US, levels of academic achievement, listening and speaking skills, reading and writing skills and gender. Results show that interaction with Mexican students raised levels of anxiety and that such strategies such as avoidance were used to reduce anxiety. In relation to Pappamihiel's study. Na 
in 2007, surveyed 115 Chinese high school students and found that these learners have high anxiety in learning the English language. Specifically she discovered that males have higher anxiety in learning English than their female counterparts. Moreover, she also found out that high anxiety plays a debilitative role in high school students language learning. This type of language anxiety causes the learner to "flee" from the learning task to avoid further anxiety (Na, 2007). Moreover, Ohata (2005) examined the nature of language anxiety from the perspective of five Japanese learners of English studying in the US. With the use of self-reflective accounts of the emotional difficulties experienced by these language learners, she found that characteristics of language anxiety are influenced by Japanese cultural norms or expectations they have acquired through numerous socialization processes in Japan. It seems that their cultural practices such as hesitating to express one's own ideas or not being assertive, caused them anxieties in their interaction with others. Williams and Andrade (2008) conducted a survey among 243 Japanese students in 31 English conversation classes at four universities in Japan. They found that language anxiety was often associated with the output and processing stages of the language learning process. Furthermore, they also discovered that students attributed their anxieties are caused by their teachers and classmates.

Foreign language anxiety has three varieties. Communication apprehension occurs in cases where learners lack mature communications skills although they have mature ideas and thoughts. It refers to a fear of getting into real communication with others. On the other hand, test anxiety is an apprehension towards academic evaluation. It could be defined as a fear of falling in tests and an unpleasant experience held either consciously or unconsciously by learners in many situations. This type of anxiety concerns apprehensions towards academic evaluation which is based on a fear of failure (Horwitz and Young, 1991). Finally, fear of negative evaluation which is the avoidance of evaluative situations.

Watson and Friend (1969, cited in Westra, 2005) defined fear of negative evaluation as apprehension about others evaluations, distress over their negative evaluations, avoidance of evaluative situations and the expectation that others would evaluate oneself negatively.

Many studies have been conducted to investigate the effect of anxiety on learning. The results of studies previously conducted regarding foreign language anxiety show that learners` beliefs about learning a foreign language, teachers` beliefs about teaching a foreign language, and classroom procedures and testing are among the main sources of anxiety (Young, 1991). Some research has been done to examine the relationship between language anxiety and language achievement, showing that language anxiety is a significant variable affecting learners`achievement (Dalkilic, 2001). In another study (Koralp, 2005) examined the anxiety levels of students and the relationship among different types of anxiety. It was discovered that there is a positive correlation between text anxiety and fear of negative evaluation.

However, a few studies have concerned with the sources of language anxiety and fear of negative evaluation. For example, according to Horwitz et al. (1986), fear of negative evaluation is triggered by the teacher as a fluent speaker and the classmates. In this regard, Young (1991) argued that the reason why learners do not participate in the classroom activities is the fear of making verbal error.

Investigation on the correlation between foreign language anxiety and fear of negative evaluation is an issue that has attracted little attention in language learning research (Kitano, 2001). The number of studies conducted in this regard is too limited. For instance, Aydin (2008) investigate the sources and levels of fear of negative evaluation as well as language anxiety among Turkish students. He found that there was a significant correlation between language anxiety and fear of negative evaluation. As said, related studies are limited and more work is needed to make strong claims. So, the present study also aims to investigate the levels and sources of language anxiety on the part of EFL learners and examine the relationship between language anxiety and fear of negative evaluation among EFL learners in another context. This study also aims to investigate whether there is any difference between female and male students in terms of levels of anxiety.

The results of the previously conducted studies regarding foreign language anxiety indicate that personal and impersonal anxieties, learners' beliefs about learning a foreign language, teachers' beliefs about teaching a foreign language, classroom procedures and testing are among the main sources of anxiety (Young, 1991). Furthermore, a review of the related literature reveals that the level of language course, language skills, motivation, proficiency, teachers, tests, and culture (Bailey, 1983; Ellis and Rathbone, 1987; Young, 1990; Price, 1991; Sparks and Ganschow, 1991; Oxford, 1992) are other factors arousing anxiety. However, it should be noted that prior studies focused on the identification of foreign language anxiety. For instance, Horwitz (1986) developed the Foreign Language Anxiety Scale (FLAS) to measure communication apprehension, test anxiety, and fear of negative evaluation. The results of the this study suggest that language anxiety is distinct from other types of anxiety.

The findings of the previous studies also indicate that there exists a significant correlation between foreign language anxiety and fear of negative evaluation, an issue that has attracted little attention in language learning research (Kitano, 2001). According to Horwitz et al. (1986), fear of negative evaluation is triggered by the teacher as a fluent speaker and the classmates. Young (1991) argued that the reason why learners do not participate in the classroom activities is the fear of committing a verbal error. Similarly, Price's study (1991) indicated that learners are afraid of making pronunciation errors in classroom. Finally, speaking in front of their peers is another source of anxiety in learning a foreign language (Koch and Terrell, 1991).

A review of available literature indicates that related studies conducted in Turkey are too limited. In the process of analysis, first and foremost, the reliability coefficient of IAS in Cronbach's Alpha Model, a model of internal 
consistency based on the average interitem correlation, was computed and compared to the coefficients found in previous studies. The reliability coefficients indicated that the scales of the FLA and FNE administered to measure the levels of language anxiety and fear of negative evaluation display a high level of reliability. Speaking more specifically, the reliability coefficients were found to be 0.91 for FLAS and 0.93 for the scale of FNE. The scale developed by Horwitz et al. (1986) proved to be reliable with the coefficient of .93 in Alpha model and the test-retest coefficient of .83 .

The first research question concerned the levels and sources of language anxiety and fear of negative evaluation of foreign language learners. Hence, the findings about the levels and sources are presented in Table 1 and 2 in descending order. These values indicate that EFL learners suffered from language anxiety due to certain anxiety-provoking factors. First, the findings reveal that learners experienced language anxiety when they were not prepared for the lesson. Second, communication apprehension felt towards teachers, peers and native speakers was suggested as a factor provoking anxiety. Third, for most of the students, teachers' questions and corrections in the classroom environment were among the factors intensifying their anxiety. As the values indicate, among other sources arousing anxiety were fear of speaking during classes, concerns about making mistakes, fear of failing classes, test anxiety, and negative attitudes towards English courses. The values presented in Table 2 demonstrate that learners also suffered from fear of negative evaluation. First of all, foreign language learners had the fear of negative judgments by and leaving unfavorable impressions on others. Besides, others' negative thoughts and fear of making verbal or spelling mistakes, fear of shortcomings noted and the faults found by others and the fear of disapproval by others are other sources causing fear of negative evaluation. To summarize the findings, as the mean values were found to be 2.61 for language anxiety and 2.89 for fear of negative evaluation, it could be concluded that foreign language learners suffered both from language

\section{MEthodOLOGY}

\section{A. Participates}

The sample of the study consisted of 61(22males, 39females) students studying English literature at Ilam University. The group covered freshmen ( 5 males, 13females), sophomores ( 8 males, 11 females), and seniors ( 9 males, 15 females). Their average age was 22. They had all studied English during high school education. A Descriptive statistical analysis was used in analyzing the data that was collected.

\section{B. Instrument}

Instruments used to collect data consisted of a foreign language classroom anxiety scale adapted from FLCAS developed by Horwitz et al. (1986) and a scale for fear of negative evaluation (FNE) developed by Leary (1983). The first part of questionnaire includes biodata questions. The items in both the FLCAS and the scale of FNE were answered within a scale ranging from one to five.

FLCAS is based on the analysis of potential sources of anxiety in a language classroom. It integrates three related anxieties (communication apprehension, test anxiety, and fear of negative evaluation) as suggested by Horwitz et al. (1986). This scale includes 33 items, of which 8 items are related to communication anxiety, 9 items to fear of negative evaluation, and 5 items to test anxiety, and remaining 11 items are put in a group named anxiety of English class. Descriptive analysis was performed to calculate mean and standard deviation of each item and each type of anxiety to obtain the general situation of students` anxiety in classroom. The Foreign Language Classroom Anxiety Scale (FLCAS) designed by Horwitz et la. (1986) was used to obtain data for this study. Horwitz and his colleagues made a unique contribution to the identification of the scope of foreign language anxiety by developing this systematic instrument. Horwitz et la. suggest that significant foreign language anxiety is experienced by many learners in response to at least some aspects of foreign language learning. This concept has been examined and used by several studies on language anxiety (Aida, 1994; Cheng, 1998; Liu, 2006; Saito, Garza \& Horwitz, 1999; Yan, 1998)

\section{Data Collection and Data Analysis}

Procedure includes the administration of instruments and statistical analysis. FLCAS and the scale of FNE were administered by author. The collected data were analyzed using SPSS 16.0 software. To find the levels and sources of the language anxiety and fear of negative evaluation, the means and standard deviations were computed. Pearson correlation coefficients were calculated to determine the relationship between language anxiety and fear of negative evaluation.

\section{RESULTS AND FINDINGS}

The results of this study were to three folds: First determining the state of anxiety and general level of different kinds of anxiety. Second, finding sources of foreign language classroom anxiety and fear of negative evaluation; third, finding correlation between these two variables. Descriptive analyses, presented in Table 1, indicated that participants had the feeling of anxiety. Based on Horwitz et al. 'interpretation, students who have average around 3 are considered slightly anxious. 
TABLE 1:

THE MEAN OF PARTICIPANTS`SCORES

Descriptive Statistics
\begin{tabular}{|l|l|l|l|l|l|}
\hline & N & Minimum & Maximum & Mean & Std. Deviation \\
\hline $\begin{array}{l}\text { Participants`Scores } \\
\text { Valid N (listwise) }\end{array}$ & 61 & 1.67 & 4.24 & 3.0468 & .55285 \\
\hline
\end{tabular}

Moreover, through the computation of means and standard deviations of each kind of anxiety, it was found that students` fear of negative evaluation, the mean of which reached 3.2011, was higher than other kinds of anxiety. Table 2 shows means and standard deviations of students in terms of each kind of anxiety.

TABLE 2:

GENERAL LEVEL OF ANXIETY OF UNIVERSITY STUDENTS

\begin{tabular}{|l|l|l|}
\hline Anxiety Variable & Mean & Standard Deviation \\
\hline Communication Apprehension & 2.9518 & .62552 \\
\hline Fear of Negative Evaluation & 3.2011 & .84951 \\
\hline Test Anxiety & 2.8459 & .59149 \\
\hline Anxiety of English Class & 2.9649 & .49994 \\
\hline English Class Anxiety & 3.0468 & .55285 \\
\hline
\end{tabular}

In order to compare males and females` levels of anxiety, another calculation was performed. As can be seen from Table 3, females means in all kinds of anxiety is higher than males, which shows that females may experience more anxiety than males in English classes. However, the result of independent sample t-test indicated there was no significant difference between males and females in anxiety (Table 4).

TABLE 3:

MALES AND FEMALES` ENGLISH CLASS ANXIETY

\begin{tabular}{|l|l|l|l|}
\hline Anxiety Variable & Gender & Mean & Standard Deviation \\
\hline \multirow{2}{*}{ Communication Apprehension } & Female & 3.0995 & .64184 \\
\cline { 2 - 4 } & Male & 2.9518 & .62552 \\
\hline \multirow{2}{*}{ Fear of Negative Evaluation } & Female & 3.3311 & .91803 \\
\cline { 2 - 4 } & Male & 2.9958 & .69147 \\
\hline \multirow{2}{*}{ Test Anxiety } & Female & 2.8769 & .57237 \\
\cline { 2 - 4 } & Male & 2.7909 & .63389 \\
\hline \multirow{2}{*}{ Anxiety of English Class } & Female & 2.9985 & .50218 \\
\cline { 2 - 4 } & Male & 2.9045 & .50156 \\
\hline & Female & 3.0765 & .658605 \\
\cline { 2 - 4 } & Male & .61311 \\
\hline
\end{tabular}

In order to find the levels and sources of foreign language class anxiety and fear of negative evaluation, the means and standard deviation of statements in FLACA scale and FNE scale were calculated. Findings related to the levels and sources are presented in Table 5 and 6.

TABLE 5:

LEVELS AND SOURCES OF FOREIGN LANGUAGE CLASS ANXIETY

\begin{tabular}{|l|l|l|}
\hline Sources of Language Anxiety & Mean & St. Deviation \\
\hline Fear of failing classes & 3.5902 & 1.22987 \\
\hline Not being prepared for questions teacher ask & 3.5738 & 1.14687 \\
\hline Fear of forgetting vocabulary and structures & 3.4098 & 1.29585 \\
\hline Fear of speaking without preparation & 3.3770 & 1.33121 \\
\hline Communication apprehension with teachers & 3.3607 & 1.25210 \\
\hline Fear of being laughed by other students & 3.0820 & 1.35763 \\
\hline Being overwhelmed by the number of rules to learn & 3.0656 & 0.99781 \\
\hline Fear of making mistake & 3.0492 & 1.30928 \\
\hline Comprehension apprehension with native speakers & 3.0328 & 1.23784 \\
\hline Test anxiety & 2.8525 & 1.19493 \\
\hline Fear of being called in class & 2.3387 & 1.05494 \\
\hline
\end{tabular}

These values show that the anxiety EFL learners experience in classroom may originate from certain sources. Firstly, the findings reveal that the prime factor which arouses anxiety among learners is fear of failing classes. Secondly, when students are not prepared for questions teachers ask they experience anxiety. Thirdly, fear of forgetting vocabulary and structures or forgetting what they know is proposed as a source provoking anxiety. As findings indicate, among other 
sources arousing anxiety was fear of speaking without preparation during the class, communication apprehension with teachers, fear of being laughed by peers, fear of making mistake, test anxiety, and fear of being called in class.

TABLE 6:

LEVELS AND SOURCES OF FEAR OF NEGATIVE EVALUATION

\begin{tabular}{|l|l|l|}
\hline Sources of Fear of Negative Evaluation & Mean & St. Deviation \\
\hline Fear of leaving unfavorable impression on others & 3.4754 & 1.42134 \\
\hline Negative judgment by others & 3.3115 & 1.36065 \\
\hline Fear of saying or doing the wrong things & 3.1639 & 3.0169 \\
\hline Fear of negative thoughts of others & 3.0169 & 1.44328 \\
\hline Fear of being noted the shortcoming by others & 2.9344 & 1.43603 \\
\hline Fear of being found fault by others & 2.9076 & 1.43417 \\
\hline Fear of disapproval by others & 2.8033 & 1.30153 \\
\hline
\end{tabular}

The values presented in Table 6 indicate that learners also suffered from fear of negative evaluation. The first source of fear of negative evaluation is suggested as fear of leaving unfavorable impression on others. Besides, negative judgment by others, fear of saying or doing wrong thing, fear of negative thoughts of and being noted the shortcoming by others, and fear of being found fault by and disapproval by others are other sources causing fear of negative evaluation. In general, the values demonstrate that learners both suffer from language anxiety in class and fear of negative evaluation.

Pearson correlation was calculated to determine the relationship between language anxiety and correlation between fear of negative evaluation and language anxiety.

TABLE 5:

CORRELATION BETWEEN ANXIETY AND FEAR OF NEGATIVE EVALUATION. Correlations

\begin{tabular}{|ll|l|l|}
\hline & anxiety & FNE \\
\hline anxiety & Pearson Correlation & 1 & $450^{* *}$ \\
& Sig. (2-tailed) & .000 \\
& $\mathrm{~N}$ & 61 & 61 \\
\hline FNE & Pearson Correlation & $450^{* *}$ & 1 \\
& Sig. (2-tailed) & .000 & \\
$\mathrm{~N}$ & 61 & 61 \\
\hline
\end{tabular}

The value found from this calculation indicates that there exists significant relationship between foreign language class anxiety and fear of negative evaluation $(r=.450)$.

\section{CONCLUSION AND DisCUSSION}

This study aimed to investigate sources and levels of foreign language classroom anxiety and fear of negative evaluation as well as to determine the relationship between the two. Results of calculations showed that subjects suffer from both foreign language classroom anxiety (mean= 3.04) and fear of negative evaluation. According to the mean and standard deviation scores, females are more anxious than males in terms of each kind of language anxiety. But, the results of independent sample t-test showed that there was no significant difference between males and females $(\mathrm{p}=.431>0.05)$. It was found that fear of negative evaluation, whose mean reached 3.2011, was a serious source of language anxiety. The obtained mean scores of freshmen, sophomore, and senior students showed that senior students $(\mathrm{M}=3.33)$ experienced more anxiety than freshmen (2.97) and sophomores (2.69).

Findings of computation of mean and standard deviation of statements of FLCA and FNE scales demonstrated that the main sources of language anxiety were fear of failing class, unpreparedness of teachers` questions, fear of forgetting vocabulary and structures. And main sources provoking fear of negative evaluation was leaving unfavorable impressions on others, negative judgment by others, and fear of doing and saying wrong things. Calculating values demonstrated that the fear of negative evaluation is a strong source of foreign language class anxiety.

According to the results of previous research, communication apprehension is a significant source of anxiety (Koch and Terrell, 1991; Price, 1991, cited in Aydin 2008). Although Young (1991) stated that teachers` beliefs about teaching a foreign language is one of the factors provoking anxiety, based on the results of this study there are additional factors such as not being prepared for questions the teacher ask ,communication apprehension with teachers, and teachers' correction, which play an important role in determining the level of anxiety. Furthermore, the findings of this study demonstrate that anxiety can prevent learners from applying correct vocabulary and structures while speaking. The findings are almost in line with results that Aydin found among Turkish students. The result of correlation analyses showed that there is a correlation between foreign language anxiety and fear of negative evaluation.

Regarding the effect anxiety can play in learning a language, Krashen (1985) maintained that anxiety inhibits the learners`ability to process incoming language and short-circuits the process of acquisition. Furthermore, Crookal and 
Oxford (1991, cited in Wörde 2003) reported that serious language anxiety may cause problems with self-esteem, selfconfidence, and risk- taking ability and ultimately hamper in proficiency in second language.

Given the role anxiety plays in learning, teachers and administrators should take it serious and attempt to reduce the effects of it on the process of students` learning. According to Horwitz and his colleagues (1986), educators have two options when dealing with anxious students: 1) they can help them to cope with the existing anxiety provoking situations; or 2) they can make the learning context less stressful.

Studies that have worked on this issue all suggest that instructors play a significant role in the amount of anxiety each student's experience in class (Price 1991; Young 1990; cited in Wörde 2003). Wörde, in his study in which he interviewed many students, reported those teachers who provide a supportive and understanding environment, who employ nonthreating teaching methods and who use appealing and relevant topics may enhance the foreign language learning. His interviews also indicated an atmosphere of cordiality, communality, and friendship among students themselves seems to reduce learners` anxiety. In this respect, Samimy and Rardin (1994) also reported that group solidarity may intensify language learning.

Given the paramount role instructors play in reducing amount of anxiety among learners, they are recommended to employ various psychological strategies in classroom.

\section{REFERENCES}

[1] Aydin, S. (2008). An investigation on language anxiety and fear of negative evaluation among Turkish EFL learners. Asian EFL Journal. 30(1),421-444

[2] Blau, A. (1955). A unitary hypothesis of emotion: Anxiety, emotions of displeasure and affective disorders. Psychology Quarterly, 24, 75- 103.

[3] Dalkilic, N. (2001). An investigation into the role of anxiety in second language learning. Unpublished Ph.D. dissertation, Turkey.

[4] Ellis, R. (1994). The study of second language acquisition. Oxford: Oxford University Press.

[5] Gardner, R.C. (1985). Social psychology and second language learning: The role of attitudes and motivation. London : Edward Arnold.

[6] Gardner, R. C. \& MacIntyre, P.D. (1993). On the measurement of affective variables in second language learning. Language Learning,43, 157-194.

[7] Horwitz, E. K., Horwitz, M. B., Cope, J. (1986). Foreign language classroom anxiety. Modern Language Journal, 70 (2), $125-$ 132.

[8] Horwitz, E. K. \& Young, D.J. (Eds) (1991). Language anxiety: From theory and research to classroom implications. Englewood Cliffs, NJ: Prentic Hall.

[9] Kitano, K. (2001). Anxiety in the college Japanese language classroom. The Modern Language Journal, 85(4), 549-566.

[10] Koralp, K. (2005). A retrospective analysis of the English language learning anxiety experienced by prospective teacher of English. Unpublished MA thesis.Turkey .

[11] Speilberger, C. (1983). Manual for the state- trait anxiety inventory. Palo Alto, Calif: Consulting Psychologists Press.

[12] Tanveer, M. (2007). Investigation of the factors that cause language anxiety for ESLIEFL learners in learning speaking skills and the influence it casts on communication in the target language. Doctoral Dissertation. University of Glasgow.

[13] Westra C. Dozois, J.A., Srewart, H. (2005). The validity of the brief version of the fear of negative evaluation scale. Anxiety Disorders, 19,345-359

[14] Wörde, R. V.(2003). Students' perspective on foreign language anxiety. Inquiry. Volum 8, Number 1.Retrieved from internet.http://www.vccaedu.org.

[15] Young, D. J. (1991). Creating a low- anxiety classroom environment: What does language anxiety research suggest? Modern Language Journal, 75, 420- 439.

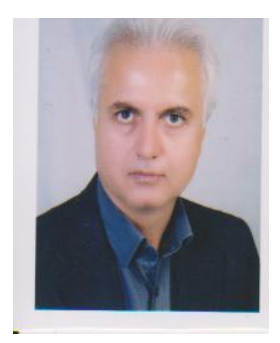

Mohammad Bagher Shabani holds a Ph.D. in ELT from university of Mumbai, India. He has published widely in both national and international conferences and has published in both national and international journals. His areas of interest include Methodology, second language skills and sociolinguistics. 